\title{
Case Study: USAID's Partnership with Walmart and the Implications for Corporate Engagement
}

이택근 (KOICA USAID 주재원)

\section{목 차}

I. Introduction

II. In-depth Analysis of Ongoing Program "Sustainable Agriculture and Women's Economic Empowerment”

III. Lessons Learned from Partnership with Walmart

IV. Conclusions

\section{Introduction}

As the world's largest retailer, Walmart plays a unique role in the global economy and has shown increasing interest in collaborating with USAID. USAID has identified Walmart as one of its top 40 corporate partners and has established a relationship manager to maintain a strategic dialogue. The two organizations can use their combined reach to address challenges with the potential to influence sustainable development and improve livelihood security.

USAID has been collaborating with Walmart in Latin America and the Caribbean (LAC) since 2002. Engagements have centered on providing training, financial support and market opportunities to small-scale farmers, particularly women, artisans and other producers in Central America (El Salvador, Guatemala, Honduras, Nicaragua) and Brazil; and creating employment for at risk youth (El Salvador). In 2011, as opportunities to collaborate increased, USAID and Walmart signed an MOU to better coordinate agricultural partnerships in Central America. 
USAID-Walmart partnership enters new era with the corporation's release of "Women's Economic Empowerment Initiative" in 2011 which represents the corporation's effort to improve the lives of women workers and farmers around the world. Despite some criticism from activists that the initiative meant to ${ }^{1)}$ deflect attention away from increasing gender discrimination lawsuits against the retailer, it created new opportunities to explore options for strategic partnership between the two organizations, which in turn led to the collaborations in Bangladesh and Rwanda.

Based on long-term partnership, USAID and Walmart could develop strong trust and a shared vision regarding sustainable development and came to recognize the mutual benefits strategic partnerships could bring to their business and development needs. This report looks back on USAID's partnerships with Walmart which have evolved over the past 12 years. From current collaborations in Bangladesh and Rwanda, several implications for strategic partnership with business partners will be addressed.

제I장

제 II장

섹

터

\section{History of USAID-Walmart Partnership}

USAID's partnership with Walmart started from a joint effort to help develop Salvadoran handicrafts in 2002. The two organizations have since concluded 13 partnerships in the Latin American and Caribbean region, and are expanding their collaboration to other regions including Asia and Africa. Walmart's pursuit of sustainability objectives and its emphasis on global responsibility have been providing new momentum for the two organizations to identify shared development priorities and strengthen strategic partnerships.

\section{Previous Partnerships with Walmart}

\begin{tabular}{c|l|c}
\hline Host country & \multicolumn{1}{|c|}{ Project title } & \multicolumn{1}{|c}{ Duration } \\
\hline \multirow{5}{*}{ El Salvador } & Youth and Community Development Program & 2012 2016 \\
\cline { 2 - 3 } & Improving Access to Employment Program & 2009 2013 \\
\cline { 2 - 3 } & Small and Medium Enterprise Development Program & 2012 2015 \\
\cline { 2 - 3 } & Alternatives (MAREA) & 2009 2014 \\
\cline { 2 - 3 } & Artisan Development Program (completed) & $2002 ~ 2009$ \\
\cline { 2 - 3 } & Agricultural Diversification Program (completed) & $2006 \sim 2009$ \\
\cline { 2 - 3 } & Export Promotion Program & $2006 \sim 2009$ \\
\hline Honduras & Convenio Walmart/ACCESSO program & $2011 \sim 2015$ \\
\hline
\end{tabular}

1) Walmart Announces Global Women’s Economic Empowerment Initiative/ www.philanthropynewsdigest.org/news/walmart-announces-global-women-s-economic-empowerment-initiatice 


\begin{tabular}{c|l|c}
\hline Host country & \multicolumn{1}{|c|}{ Project title } & \multicolumn{1}{|c}{ Duration } \\
\hline \multirow{4}{*}{ Guatemala } & Inclusive Market Alliance for Rural Entrepreneurs (IMARE 1) (completed) & 2007 2010 \\
\cline { 2 - 3 } & Inclusive Market Alliance for Rural Entrepreneurs 2 (IMARE 2) & 2010 2014 \\
\cline { 2 - 3 } & Health and Education Alliance Guatemala (Global Health Partnership) & $2005 \sim 2010$ \\
\cline { 2 - 3 } & Supporting Small Rural Farmers & $2011 \sim 2014$ \\
\cline { 2 - 3 } & Continuous Improvement in the Central America Workplace (CIMCAW) (completed) & 2003 2008 \\
\hline \multirow{2}{*}{ Brazil } & TransFair USA/Café Bom Día (completed) & $2007 \sim 2010$ \\
\hline \multirow{2}{*}{ Nicaragua } & $\begin{array}{l}\text { Alliance to Create Opportunities for Rural Development through Agro-Enterprise } \\
\text { Relationships (ACORDAR) }\end{array}$ & 2007 \\
\hline
\end{tabular}

\section{Current Engagements between USAID and Walmart}

- Sustainable Agriculture and Women's Economic Empowerment (for detailed information on this program, see the cases on pages 4 6.)

O Bangladesh: Walmart is providing support to the Accelerating Agriculture Productivity Improvement Project implemented by the International Fertilizer Development Center. The project will train 40,000 women vegetable farmers using deep placement urea technology.

O Rwanda: Walmart is providing support for the Integrated Improved Livelihood Program implemented by Global Communities. 50,000 women will be trained in horticulture and other value chains. Walmart's $\$ 1$ million will likely be matched by $\$ 1$ million from the Mission for complimentary nutrition programming

\section{- Improving Access to Employment Program, EI Salvador, 2009 2013}

○ Workforce training and curriculum development, El Salvador, 2009 2013

○ Career counselling and technical and vocational training center information

Improving the information system on workforce supply and demand

\section{- Convenio Walmart, Honduras, 2011 2015}

USAID partnership with Walmart and the Honduran Ministry of Agriculture,

○ Promotes agricultural development projects in areas with high rates of food insecurity

O USAID provides training, technical assistance, and access to agricultural inputs to small farmers that improve crop quality and production efficiency, 
O Walmart provides market opportunities for producers by selling their products through its retail chain.

\section{- MOU Supporting Small Rural Farmers, Central America , 2011 2014}

O USAID has a Memorandum of Understanding (MOU) with Wal-Mart for activities in Central America, and they have worked with Feed the Future programs in the focus countries in that region.

\section{口 Walmart's Global Responsibility}

As the world's largest retailer committed to social investment, Walmart has been pursuing sustainability as one of its highest priorities for business. The progress against sustainability objectives has been made public through annual 'Global Responsibility Report'. Some of the sustainability objectives laid out in its latest annual report(Global Responsibility Report 2013) are:

口 Provide training to 1 million farmers and farm workers by 2015 , of which half will be women

口 Under Walmart's Women's Empowerment Initiative, help 500,000 women participate more fully in the agriculture supply chain (goal by 2016)

$\square$ Raise the income of the small and medium-sized farmers Walmart sources from by 10 to 15 percent

口 Sell $\$ 1$ billion sourced from 1 million small and medium-sized farmers

- Provide training to support 200,000 women to get their first retail or service sector job

$\square$ Purchasing and selling sustainable products--including developing supply chain innovations in part to eliminate 20 million metric tons of GHG emissions

To meet these ambitious objectives, Walmart and the Walmart Foundation look for partnership opportunities with the following characteristics:

$\square$ Project must have substantial scale (impact) in terms of farmer outreach

- High share of female participation in program is critical; alternatively, there must be potential to increase share of female participation.

- Walmart wants to get maximum leverage for its investment and is looking for cost - effective training approaches

- Ideally looking to partner in markets where Walmart is currently operating, sourcing or is a planned expansion market

Walmart and the Walmart Foundation would look to support programs in areas where it has experience and can add value, such as:

口 Training curriculums and approaches focused on women's training.

\ Training initiatives focused on developing linkages between farmers and markets. 


\section{In-depth Analysis of Ongoing Program "Sustainable Agriculture and Women's Economic Empowerment"}

As a growing number of corporations expand their operations globally and face challenges ${ }^{2)}$ threatening their supply chain stability and the security of global operating environments, USAID sees more opportunities to work with those corporate partners whose long-term business interests are at stake in emerging markets. ${ }^{3)}$ The shift in business strategies toward engagement with other partners and the emergence of new business models which requires other partners to develop services and products targeted at the poor will further drive business partners to contemplate strategic relationships with the government sector.

In 2011, Walmart announced "Women's Economic Empowerment Initiative" which demonstrates the corporation's renewed ambition to pursue socially conscious business across the globe. The initiative gave USAID and Walmart momentum to explore business and development opportunities and eventually led to partnership investments in Bangladesh and Rwanda. This section looks into the two projects in detail, which indicate how strategic partnerships with business partners could bring benefits to both the pubic and private-sector partners involved.

\section{[Case 1]}

\section{Leveraging resources from Walmart in Accelerating Agriculture Productivity Improvement (AAPI) project to scale up the Fertilizer Deep Placement (FDP) technology to women farmers}

\section{Introduction and Background}

Walmart funding would allow 40,000 small scale women farmers to be trained on the use of a fertilizer technology that will increase vegetable production. Given the expected rate of adoption of this technology by other women farmers who will learn from those directly trained by the project, Walmart funding would lead to the adoption of this technology by an estimated 160,000 women farmers, leading to better household nutrition and increased income for the women.

2) Partnering with USAID: A Guide for Companies, p. 4.

3) Seizing the Opportunity in Public-Private Partnerships STRENGHTHENING CAPACITY AT THE STATE DEPARTMENT, USAID AND MCC, p.5 6 
IFDC is implementing the USAID funded AAPI project to address the key challenges of increased food security and poverty alleviation in Bangladesh. The strategic approach involves the rapid diffusion of fertilizer deep placement (FDP) technology.4) This technology is a proven, resource-conservation and environmentally friendly sustainable technology that enables farmers to increase rice yields by $15 \%$ 20\% with $30 \%$ less use of nitrogen fertilizers. While the focus to date has been on the use of this technology with rice, it is being adopted for vegetables and other non-rice crops as well. Initiated in September 2010, the five year AAPI project involves intensive demand and supply-related activities to increase farmer knowledge and support development of a supply system to afford farmers access. So far about 2.8 million farmers have adopted the FDP technology in 0.9 million hectares of rice and vegetable lands with a $\$ 300 /$ ha incremental average net income realized per farmer.

The FDP technology for vegetables has a great deal of potential for scale up among women farmers. Financial support from Walmart could drive this scale up effort, resulting in improvements in women's income and the nutritional status of women and children through consumption of their own produce.

\section{Goal and Objectives}

Goal: To increase incomes and food security for rural women;

Objective: (a) rapidly increase development, dissemination and adoption of yield enhancing technologies for rural women; (b) improve the nutritional status of the rural women and their family members, and (c) increase rural women's incomes through the sale of vegetables and ownership of small agro-enterprises.

\section{Targeted Beneficiaries/outputs}

Direct:

- About 40,000 women farmers will be trained in the FDP technology for vegetables

- 8,000 hectares of land will be brought under vegetable cultivation with FDP

- In addition to increased household consumption of vegetables, the women will earn on average about $\$ 80$ per year in net income from sales of vegetables ${ }^{5)}$

- $10 \%$ less use of fertilizer

4) UDP involves point placement of a large fertilizer pellet (up to 2.7 grams by weight) near the root zone of the plant. This reduces fertilizer nitrogen losses and increases crop uptake efficiency of the fertilizer and is an environmentfriendly technology. UDP technology is well suited to small, resource-poor farmers, including women

5) Given the small size plots (on average) on which these women farmers grow vegetables, this $\$ 80$ increase in net income is a significant increase. 
- About 200,000 men, women, and children will benefit directly from the initiative

Indirect: Average adoption rate of new technology is four farmers per farmer trained by the AAPI project. Accordingly, the expectation is that:

- All together about 160,000 women farmers will adopt the technology in 32,000 hectares of vegetable growing land

\section{Additional Funding}

- It will cost approximately $\$ 40$ per farmer to scale up the FDP technology among the projected 40,000 new women vegetable farmers.

- It costs $\$ 2,800$ per new briquette machine and it is projected that 25 new briquette machines owned by women/groups of women will be needed to meet the projected increase in demand for fertilizer pellets.

\section{Duration}

Two years, effective from October 2013

\section{[Case 2 ]}

Support to women farmers in Rwanda through the Integrated Improved Livelihood Program (IILP)-USAID Ejo Heza (Kinyarwanda "Brighter Future")

\section{Background and Interventions}

$71 \%$ of the Rwandan labor force works in the agriculture sector, the vast majority as subsistence farmers. Women generally carry the agricultural burden more so than men; almost three-quarters of all women work in agriculture compared with around $60 \%$ of all men. $30 \%$ of the country's households are female-headed, and most of them are very poor. Recent studies suggest that integrating microfinance with non-financial services, such as literacy/education, business development services, and extension services, has enormous potential to address the multiple needs of the poor in a more efficient and synergistic manner.6)

The IILP, a Feed the Future initiative project, helps improve the livelihoods and food consumption of very poor Rwandans, particularly women, by helping low-income households access the financial services necessary to grow their small agriculture businesses.

6) Dunford, Christopher, et al., "How microfinance can work for the poor: The case for integrating microfinance with education and health services," Freedom from Hunger discussion paper, 2007. 
The project also seeks to bring Rwanda's poor into priority value chains - namely, the maize, beans, and dairy value chains - to improve their livelihoods. Training programs in the maize and beans value chains are well advanced, and IILP is now beginning the process of rolling out dairy training activities. Finally, the project integrates nutrition messaging throughout its program activities to encourage farmers to consume higher-quality foods.

Walmart Foundation funding would allow 20,000 to 25,000 smallholders, mostly women, to receive training that will enable them to enter the dairy value chain. Training topics would include animal health, feeding, reproduction, hygiene, and milk handling techniques.

Walmart Foundation funding will support the transfer of a proven training method developed under another Feed the Future project in the maize and beans value chains. The STICKS methodology (Scalable Tracker for Imparting Certified Knowledge and Skills) uses a durable, water proof small poster and inserted "stick" as training material that features illustrations and key learning points. The tool can also be used during refresher trainings and as part of performance monitoring.

Beneficiaries of Walmart Foundation funding will be those targeted by the Government of Rwanda's successful "One Cow per poor Family" initiative, a pro-poor program rooted in the methodology pioneered by Heifer, another Arkansas-based organization, in which recipients of cows agree to share offspring with other families in need.7)

As a complement to the training, Foundation funding will allow these same beneficiaries to form Savings and Lending groups. Providing the poor with access to microfinance will help them maintain basic food security and nutrition by smoothing their consumption and providing them with the financial flexibility to deal with unexpected health emergencies.8)

With a budget of $\$ 500,000$ and a marginal per-beneficiary cost of $\$ 20$, the IILP offers the Walmart Foundation the opportunity to extend the program's reach from its current target of 75,000 farmers over five years to approximately 100,000.The majority of beneficiaries will be women.

\section{Expected outcomes attributable to Walmart Foundation funding}

1. Approximately 25,000 additional farmers reached;

2. Increased milk production among beneficiary households by at least $30 \%$, and increasing beneficiary household incomes by at least $20 \%$;

7) Heifer International (http://www.heifer.org/) was the beneficiary of a three-year, $\$ 1.5$ million grant from USAID in Rwanda awarded in 2000.

8) Rosenberg, Richard, “Does Microcredit Really Help Poor People?” CGAP Focus Note No. 59, January 2010. 
3. 1,000 Savings and Lending groups formed, with $35 \%$ of members gaining access to formal financial services; and

4. Savings and Lending group members will benefit from additional project services, including nutrition education. $80 \%$ are expected to have increased their knowledge of sound dietary practices, with $55 \%$ consuming a more diversified diet.

\section{Duration}

One year, effective from October 2013

\section{Implementer}

CHF International/Global Communities

\section{Budget}

$\$ 500,000$ 
$<$ FIGURE 1> PARTNERSHIP BUILDING PROCESS of the PROGRAM "SUSTAINABLE AGRICULTRURE AND WOMEN'S ECONOMIC EMPOWERMENT"

1. Walmart asks for information on existing USAID projects that have high women farmer training numbers.

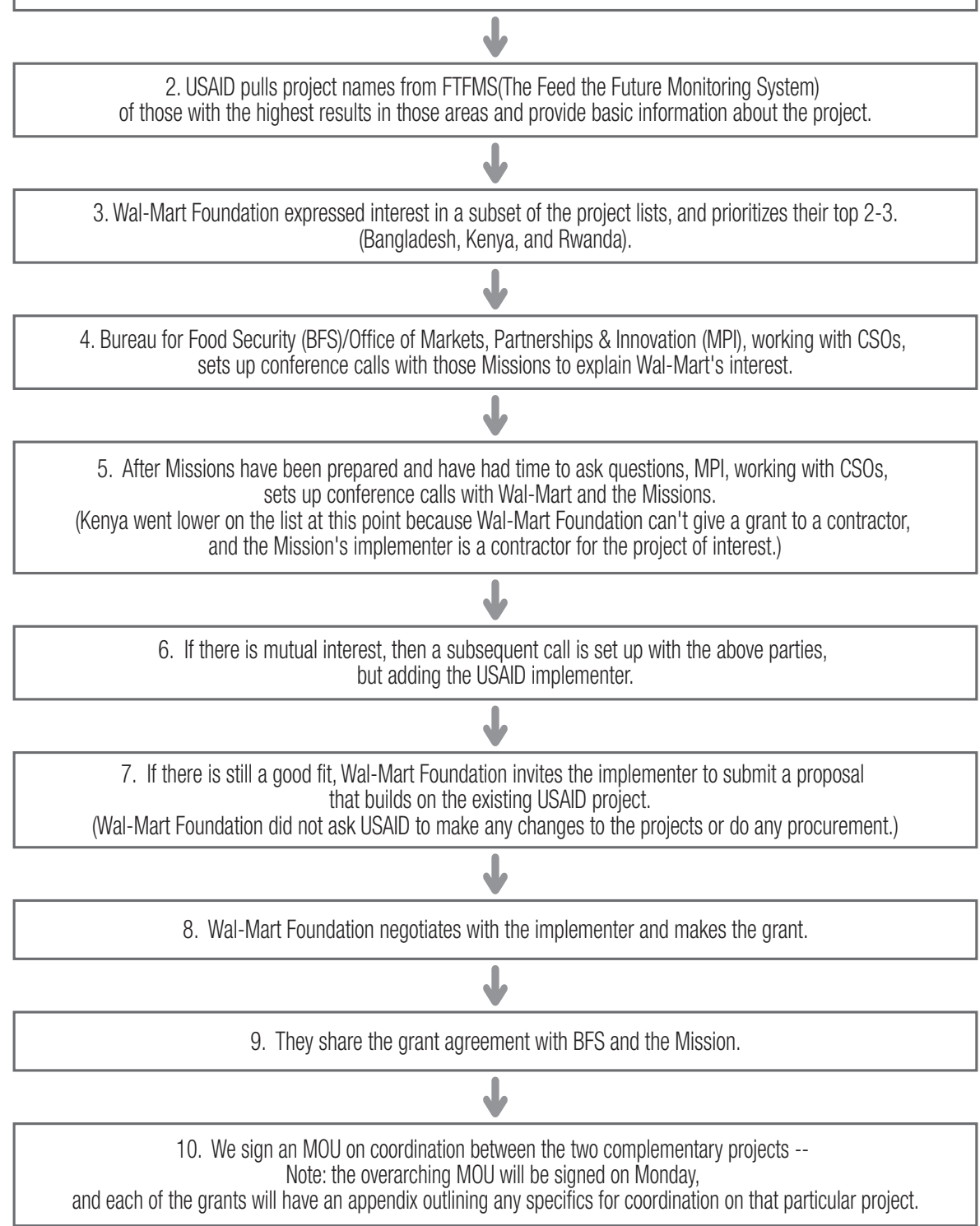




\section{Major Features of Partnerships with Walmart}

\section{Joining Existing USAID Programs}

In the two cases being examined, no acquisition \& assistance requirements were needed for forming partnerships with Walmart and selecting implementing partners. Based on Walmart's commitment to CSR initiatives, USAID and Walmart could readily identify areas of common interest in supporting sustainable agriculture and women's empowerment. After discussions with USAID missions in Bangladesh and Rwanda and subsequent negotiations with relevant implementers, Walmart decided to expand the existing USAID projects in each country.

The design and planning of activities to be funded by Walmart and the terms and conditions of grants were negotiated between Walmart and respective implementing partners (IFDC in Bangladesh, CHF International in Rwanda) while USAID playing a role of facilitator between the two private partners throughout the partnership building process.

\section{Areas of Common Interests}

As business operations expand into the developing world, CSR initiatives with a development/ emerging market focus are becoming a critical link between development cooperation and business activities. As the world's largest retailer operating in 26 countries, Walmart pursues a number of CSR initiatives focusing on social, local, environmental and company responsibilities. Walmart's proactive CSR strategy and full dialogue with USAID in search of the overlap of development and business interests made it easy for the two organizations to find areas of common interests and jointly define development challenges to be addressed.

\footnotetext{
$\square$ Walmart's Initiatives with a Development Focus

- Sell $\$ 1$ billion in produce that originate from 1 million small and medium farmers

$\square$ Raise income of the small and medium farmers Walmart sources from by 10 to 15 percent

口 Train 1 million farmers and farm workers, of which half should be women(goal by 2015)

口 Under Walmart's Women's Empowerment Initiative, help 500,000 women participate more fully in the agriculture supply chain (goal by 2016)

口 Women in Factories program - empower 60,000 women working in factories that supply products to Walmart and other retailers in India, Bangladesh, China and Central America by teaching critical life skills related to communication, hygiene, reproductive health, occupational health and safety, identifying personal strengths and gender sensitivity

$\square$ Provide training to support 200,000 women to get their first retail or service sector job

口 Double sourcing from women-owned businesses in Walmart's international retail markets

- Purchasing and selling sustainable products including developing supply chain innovations in part to eliminate 20 million metric tons of $\mathrm{GHG}$ emissions
} 


\section{Mutual Learning and Expansion of Partnership}

Different institutional cultures and processes pose major obstacles to collaboration between government agencies and private partners. Negative perception of the private sector could also impede the creation of strategic partnerships with private businesses. In the case of partnership with Walmart, full dialogue and knowledge sharing based on long-standing partnership between the two organizations made it possible for USAID and Walmart to learn from each other and identify promising opportunities for further collaboration.

口 Ongoing Discussions on Collaboration with Walmart

$\square$ West Africa Regional: Walmart and USAID are currently in discussions around supporting the African Cashew Alliance in Ghana and Kenya. This project explicitly aligns with Walmart's business sustainability interests. 35,000 farmers would be trained in value added cashew processing.

$\square$ Workforce Development: Walmart and the E3 and IDEA offices are currently in discussions around developing / supporting a cost effective way to provide soft skills training to millions of youth. This is in conjunction with a consortium of private sector companies (Hilton, Hyatt, McDonald's, among others) working with USAID, and long-time USAID partner - International Youth Foundation(IYF). E3(Bureau for Economic Growth, Education and Environment)/ED(Office of Education) is coordinating this discussion.

$\square$ Women's economic empowerment: This area is one of Walmart's top priorities in the MOU. Conversations with USAID/Mexico on workforce development initiatives in conjunctions with Walmart's School of Retail that trains youth for retail and service sectors jobs.

- Climate change discussions led by E3(Bureau for Economic Growth, Education and Environment) including: Proposal in Bangladesh and India to train factory managers to reduce energy and water usage, Possible work with USG Tropical Forest Alliance 2020 to decrease deforestation, being co-created by USG and the Consumer Goods Forum

\section{Synergistic Effects from Partnership}

The purpose of partnership building is to combine expertise and resources of diverse partners in order to address development challenges that no one partner could solve alone. Synergy from partnership could be achieved when all partners' activities are aligned with their shared values and goals.

In the cases being examined, Walmart agreed to build on USAID's existing projects for efficiency and quick action. Through partnerships with Walmart, USAID has benefited from the amplification effects resulting from the expanded scope of the original projects while Walmart achieved its objectives by utilizing USAID's agricultural expertise and local networks.

The complementary and synergistic effects derived from strategically aligning USAID's original projects with Walmart's new/complementary projects could not have been achieved if each organization had elected to work apart. 


\section{Lessons Learned from Partnership with Walmart}

\section{Linking CSR initiatives to Partnership Opportunities}

Building partnerships with the private sector entails a range of challenges including finding the right partners and the right shared problem with the right timing and level of resources (Runde, $2011)^{9}$. In that regard, the emergence of corporations which have avowed commitment to CSR strategy and have interest in working with the government could make it easier for USAID to find optimal business partners for collaboration.

${ }^{10}$ In Latin America, USAID has been partnering with Chevron since 2010 to provide vocational training to young people. This program was jointly developed to support Chevron's initiative of educating human talent as part of the corporation's social investment in the region.

${ }^{11)}$ In an attempt to achieve the corporation's sustainability objectives, SC Johnson is working with USAID to help Rwandan pyrethrum growers to raise their incomes and living standards by increasing crop outputs and improving the quality of the pyrethrum flowers they farm.

As more and more corporations deem social responsibility as core business values, the opportunities to build strategic development partnerships with those business partners are expected to continue to increase. In future engagement with the private sector, a full dialogue focusing on corporations' CSR strategy will help identify the intersections of business and development interests and come up with appropriate partnership models.

\section{Adding or Embedding a Partnership}

Building partnerships is a time-consuming and labor-intensive process. Although GDA was developed to allow for flexibility in funding development partnerships, business partners often feel frustrated with 12)too much time needed from initial conversations to the formal establishment of a DC-based global relationship. Procurement processes for assessing and selecting project implementing partners also take up a considerable amount of time to start the actual implementation of the project.

9) Daniel Runde, "Seizing the Opportunity in Public-Private Partnerships", STREGTHENING CAPACITY AT THE STATE DEPARTMENT, USAID, AND MCC(2011), p. 3.

10) Corporate Responsibility Report 2012, Chevron Latin America Exploration and Production (2012), p. 20.

11) Green Choices SC JOHNSON 2012 PUBLIC SUSTAINABILITY REPORT (2012), p. 29.

12) EVAUATING GLOBAL DEVELOPMENT ALLIANCES: AN ANALYSIS OF USAID'S PUBLIC-PRIVATE PARTNERSHIPS FOR DEVELOPMENT, P.5. 
In IILP Project, the Walmart Foundation extended the program's reach from its current target of 75,000 farmers over five years to approximately 100,000 while utilizing CHF International as an implementer. The AAPI project helped scale up the FDP technology among the projected 40,000 new women vegetable farmers by employing IFDC as an implementing partner.

In both cases, Walmart did not have to ${ }^{13}$ go through a preparatory relationship-building process by jumping into existing relationships and could achieve its women's empowerment goal at lower cost by contributing to existing programs as part of larger initiatives.

On the part of USAID, the administrative burden of acquisition \& assistance was reduced by relying on existing implementing partners. Instead of spending time and energy on logistical requirements, USAID could concentrate more on program design and planning with its partners, which is critical to ${ }^{14}$ timely and relevant project proposals by implementing partners.

${ }^{15}$ To facilitate an efficient and cost effective partnership formation, adding or "embedding" a partnership within an existing program should continue to be considered as a useful option for partnership development.

\section{Communication and Coordination Mechanism}

Success of partnerships often relies on strong interpersonal relationships. Frequent changes of field office staff and their varying degree of support have the potential to undermine partnerships established with the private sector. Having a relationship manager/dedicated staff based in Washington DC could significantly enhance communication and coordination among cornerstone partners and ensure continued support for partnerships.

A central point of contact could also contribute to ${ }^{16}$ the outreach and recruitment for future partnerships. For potential corporate partners which look for partnership opportunities with USAID but do not have experience working with the government sector, the technical expertise and support provided by the dedicated staff in headquarters could serve as a credible and stable resource to enter into partnership with USAID.

13) Partnering with USAID: A Guide for Companies, p.17.

14) "NGO actors have commented that writing partnership proposals requires a lot of specificity, but they take so long to go through the internal process that conditions and opportunities change, rendering the specifics of the proposal out of date and somewhat irrelevant", Seizing the Opportunity in Public-Private Partnerships STRENGTHENING CAPACITY THE STATE DEPARTMENT, USAID and MCC, p.19

15) Partnering with USAID: A Guide for Companies, p.17

16) EVAUATING GLOBAL DEVELOPMENT ALLIANCES: AN ANALYSIS OF USAID'S PUBLIC-PRIVATE PARTNERSHIPS FOR DEVELOPMENT, P.23. 
In pursuing partnerships with Walmart, the role of a Washington-based relationship manager was crucial to the effective and efficient communication and coordination among cornerstone partners. S/he has not only connected Walmart with competent implementers knowledgeable about the local development landscape but served as a focal point among USAID headquarters, mission staff and the corporate partner throughout the partnership planning and implementation process.

\section{Conclusions}

Walmart could grow to become the world's biggest retailer by aggressively enlarging its business globally since 1991. Partnerships between USAID and Walmart started in the 2000s, when Walmart enjoyed ${ }^{17)}$ recognition from various organizations and ranked top on the Fortune 500 list of America's largest companies.

The global expansion of Walmart brought the corporation to pay attention to its social responsibility which eventually led to strategic partnership with USAID in 2002 centering around collaboration in the Latin American and the Caribbean regions. Since then, USAIDWalmart partnerships have grown and evolved to collaboration in a range of areas including rural development, work force development, SME development, women's economic empowerment, etc. Today, bilateral collaboration is broadening to include additional countries in Africa and Asia.

Partnerships with Walmart in Bangladesh and Rwanda discussed in this study suggest many practical implications for public and private partnership models. It should be first noted that USAID and Walmart's pursuit of innovative partnership to address development challenges was a major driving force behind the evolution of bilateral alliance. USAID and Walmart were from the outset the central actors of the partnership formation and getting around complicated and timeconsuming logistical requirements for the selection of implementers allowed both organizations to bypass preparatory relationship-building process and to concentrate more on strategic design and planning.

Over the past 13 years, the GDA model has been at the forefront of engaging corporate partners which have the potential to bring innovative solutions to global development challenges. Through the GDA mechanism, private businesses with CSR initiatives and innovative ideas are

17) Did Walmart Wake Up? How Strategic Management Handled Walmart's Reputation, p.7 
welcomed to join USAID as co-funders and co-designers of development projects. ${ }^{18}$ They can benefit from USAID's matching funds, local knowledge and the credibility and contacts made available through the partnership model.

However, ${ }^{19}$ due to GDA's broker-in-the-middle relationship where NGOs and other implementing partners take on much of the work for partnership building and management processes, a vital dialogue between USAID and potential business partners regarding the preparation and planning of partnerships is often likely to be overlooked.

Under any process, a major concern of business partners with development-focused initiatives does not lie in going through labor-intensive and time-consuming administrative procedures but in ${ }^{20}$ addressing the central issue of doing something for people. To meet growing business case for CSR and corporate interest in partnering with the government sector, more flexible tools and practices need to be contemplated. In that sense, the features and lessons of partnerships with Walmart discussed in this study could provide useful insights not only to staff involved in private sector engagement but to global corporations committed to CSR.

\section{제 I 장

18) EVAUATING GLOBAL DEVELOPMENT ALLIANCES: AN ANALYSIS OF USAID’S PUBLIC-PRIVATE PARTNERSHIPS FOR DEVELOPMENT, P.35.

19) Seizing the Opportunity in Public-Private Partnerships, STRENTHENING CAPACITY AT THE STATE DEPARTMENT, USAID, AND MCC, p.19.

20) EVALUATING GLOBAL DEVELOPMENT ALLIANCES: An Analysis of USAID's Public-Private Partnerships for Development, p.6. 


\section{Annex}

\section{History of USAID-Walmart Partnership}

\section{El Salvador}

- Youth and Community Development Program 2012 2016;

O USAID contributed $\$ 2.45 \mathrm{~m}$ while the private sector contributed $\$ 2.55 \mathrm{~m}$

O Implemented by local foundation, Glass wing International with support from Chevron, Hanes Brand and Walmart.

O Rehabilitate at least 75 schools in poor communities and work with companies, local governments and communities to provide safe learning spaces and extra curricula activities for at-risk youth.

- Improving Access to Employment Program, 2009 2013

O Workforce training and curriculum development to prepare young people for employment at Walmart.

○ Career counseling and technical and vocational training center information

○ 4100 students (2100 women) have already benefitted, including 1030 persons (350 women) who have better employment

○ Total investment approximately $\$ 7.5$ million

O The activity is implemented by CARANA. Initially it focused on providing trained personnel for customer service in supermarkets using a specifically tailored curriculum for that entry-level position. The effort later expanded to cover cashiers, assistant managers, and fruit and vegetable handlers. Over 400 youth have been trained for different positions from which over 300 have been hired by Walmart.

- Small and Medium Enterprise (SME) Development Program 2012 2015

O Total investment of $\$ 9.6$ million

O Improvement of business development services provided by the government and private sector organizations to SMEs.

O Includes a supplier linkage initiative with Walmart's SME suppliers to identify and overcome the technical requirements and bottlenecks that limit sales increase to Walmart stores in that region.

○ Implemented by Chemonics. 
- Regional Program for the Management of Aquatic Resources and Economic Alternatives (MAREA) 2009 2014

Total investment of $\$ 12.6$ million

O Assisting an association of 84 fishermen at El Cuco beach, SanMiguel to implement sustainable production and commercialization practices of fishery products to supply all Walmart stores.

Implemented by Chemonics

- Artisan Development Program, 2002 2009 (completed)

O USAID worked with Walmart and the NGO, Aid to Artisans, to improve the quality and marketability of Salvadoran handicrafts. The Salvadoran social enterprise, Alternativa, which today operates as a broker between the artisans and larger buyers, grew out of this partnership to ensure stability.

-Agricultural Diversification Program, 2006 2009(completed)

O Contract to FINTRAC, who brought in Walmart - Fintrac helped link USAID-supported farmer associations (fruit, vegetables, horticulture) to the local buyer (Horti Fruti) for Walmart's local stores (SuperSelectos). Several of these associations continue to sell to Walmart.

- Export Promotion Program, 2006 2009 (completed)

O Innovative partnership under US-DR/CAFTA Free Trade Agreement, to help Salvadoran SMEs in need of minor quality upgrades to make products (e.g. packaging; compliance w/sanitary and phyto-sanitary rules more exportable. Walmart was one of the companies that sourced products.

\section{Honduras}

- Convenio Walmart/ACCESSO program, 2011 2015

O USAID partnership with Walmart and the Honduran Ministry of Agriculture,

○ Promotes agricultural development projects in areas with high rates of food insecurity

O USAID provides training, technical assistance, and access to agricultural inputs to small famers that improve crop quality and production efficiency,

O Walmart provides market opportunities for producers by selling their products through its retail chain. 
O Moure than $80 \%$ of produce Walmart sources locally is purchased in co-ordination with the ACCESSO technical assistance program.

S Seeks to lift 30,000 farming families out of poverty in 5 years

O Program is credited with helping strengthen agro-economic environment in Honduras. For example, farmers are using their contracts with Walmart as collateral for credit.

\section{Guatemala}

- Inclusive Market Alliance for Rural Entrepreneurs (IMARE 1), 2007 2010 (completed)

O Part of FtF supporting Guatemala's "Zero Hunger Pact" to significantly reduce the high rates of poverty and chronic malnutrition

- Inclusive Market Alliance for Rural Entrepreneurs 2 (IMARE 2), 2010 2014

O Implemented by Mercy Corps

O Project was going as planned when Walmart decided to shift its focus to Asia to meet sustainability and gender goals.

○ Green Mountain Coffee Roasters and the Nuemann Foundation stepped in to provide financial resources that were lost when Walmart departed.

$\bigcirc$ Included training and technical assistance in nutrition, climate change, and gender balance as a best practice.

- Health and Education Alliance Guatemala, 2005 2010 (Global Health Partnership)

\section{Central America}

- Supporting Small Rural Farmers, 2011 2014

USAID has a Memorandum of Understanding (MOU) with Walmart for activities in Central America, and they have worked with Feed the Future programs in the focus countries in that region. While the project itself has concluded, Walmart continues to purchase from some of the farmers who received assistance under Feed the Future.

This alliance has not produced tangible results from a regional point of view, mainly because each country was (successfully) working with Walmart and the regional MOU did not provide any additional benefit. The lesson learned here was that regional MOUs without a strong, own value proposition (such as funding) and a clear specification of contribution by each of the parties involved, tend not to be effective. 
- Continuous Improvement in the Central America Workplace (CIMCAW), 2003 2008 (completed)

O Walmart was one of numerous US retailers (including Gap, Sarah Lee, Timberland) who joined USAID to push for improvements in labor conditions in Korean and Taiwanese operated garment factories in El Salvador and Guatemala.

O The alliance led to some improvements such as lighting, ventilation, common areas etc.

○ Was unsustainable as factory managers would not embrace the program

\section{Brazil}

- TransFair USA/Café Bom Día 2007 2010 (completed)

○ 6000 small-holder coffee producers received technical training and infrastructure investments to prepare them for Fair trade certification.

○ Walmart/Sam's Club provided marketing and merchandising assistance to the farmers and sold a portion of the products in their stores.

\section{Nicaragua}

- Alliance to Create Opportunities for Rural Development through Agro-Enterprise Relationships (ACORDAR) 2007

O USAID's implementer, CRS, through ACORDAR, explored the possibility of an alliance with Walmart through HortiFruti (local Walmart entity). They held several meetings but were unable to consolidate the alliance formally. However, HortiFruti and ACORDAR producers continued to collaborate. HortiFruti purchased $\$ 488,054$ vegetables during ACORDAR implementation. 


\section{Bibliography}

EVALUATING GLOBAL DEVELOPMENT ALLIANCES: An Analysis of USAID's

Public-Private Partnerships for Development

Seizing the Opportunity in Public-Private Partnerships, STRENTHENING CAPACITY AT THE STATE DEPARTMENT, USAID, AND MCC (2011)

Did Walmart Wake Up? How Strategic Management Handled Walmart's Reputation Partnering with USAID: A Guide for Companies

Walmart Announces Global Women’s Economic Empowerment Initiative/

www.philanthropynewsdigest.org/news/walmart-announces-global-women-seconomic-empowerment-initiatice

Corporate Responsibility Report 2012, Chevron Latin America Exploration and Production (2012)

Green Choices SC JOHNSON 2012 PUBLIC SUSTAINABILITY REPORT (2012)

Rosenberg, Richard, “Does Microcredit Really Help Poor People?” CGAP Focus Note No. 59, January 2010.

Dunford, Christopher, et al., "How microfinance can work for the poor: The case for integrating microfinance with education and health services," Freedom from Hunger discussion paper, 2007. 